\title{
O exercício físico e o desenvolvimento da criança na literatura médica e pedagógica de Setecentos
}

\author{
J. V. Ferreira
}

Faculdade de Ciências do Desporto e de Educação Física da Universidade do Porto, Portugal

\author{
A. G. Ferreira
}

Faculdade de Psicologia e de Ciências da Educação da Universidade de Coimbra, Portugal

\section{RESUMO}

Acompanhando a emergência da sociedade moderna, as propostas pedagógicas dos educadores mais ilustres vão, cada vez mais, encarar a educação do corpo como um aspecto de fundamental importância.

Todavia, não se pode ignorar que as preocupações relativas ao bem-estar e equilíbrio do corpo se encontravam presentes em algumas obras médicas da primeira metade de Setecentos. Médicos e cirurgiões consideraram o exercício físico como algo de relevante na conservação da saúde.

No entanto, nas obras médicas e cirúrgicas da primeira metade do século, a preocupação dominante, senão a única, era a da preservação da saúde. Raramente, nelas se encontrava a preocupação com o desenvolvimento integral do homem. Na segunda metade do século XVIII, os médicos e pedagogos passaram a olhar a Educação Física como uma condição fundamental do desenvolvimento global do indivíduo. Neste sentido, o exercício já não era particularmente entendido apenas como necessário à preservação da saúde, mas como factor de desenvolvimento físico, base importante da formação moral. No presente estudo, pretendemos analisar os argumentos então apresentados sobre a importância da Educação Física e sublinhar as principais ideias e aspectos a definirem a tendência das propostas médicas e pedagógicas publicadas, durante o século XVIII, em Portugal.

Palavras-chave: Exercício físico, criança, desenvolvimento, ideias, médicos, pedagogos, século XVIII, Portugal.

\section{ABSTRACT \\ Exercise and Child Development on Medical and Pedagogical Literature of the 18th Century}

Following the modern society emergency the pedagogic proposals of the most famous educators will face, more and more, the body education as an aspect of major importance.

However, we could not ignore that the concerns related to body well being were already treated in some medical works of the first half of the 18th century. Doctors and surgeons considered exercise as something relevant in health preservation.

Nevertheless, in the medical and surgical works of the first half of that century, the main concern, if not the only one, was health preservation. Seldom, the concern with man's whole development was found. In the second half of the 18th century, doctors and pedagogues began to look to physical education as a fundamental condition for individual global development. In this sense, exercise was not only understood as needed for the health preservation, but also as a factor of physical development and moral formation.

In the present study, we want to analyse the arguments presented in the 18th century about the importance of physical education and to underline the main ideas and aspects that define the trends of medical and pedagogic proposals published in Portugal during this period.

Key Words: Exercise, Child, Development, Ideas, Doctors, Educators, 18th century, Portugal. 


\section{INTRODUÇÃO}

As concepções e as práticas inerentes ao passado da Educação Física, em Portugal, nunca foram alvo de grande atenção. Ainda que, durante as últimas décadas do século XX, tivessem surgido alguns títulos a permitirem-nos ir alcançando algum conhecimento sobre o assunto, eles continuaram a mostrar que os exercícios físicos não se têm mostrado interessantes à compreensão da evolução cultural do país. É certo que alguns dos trabalhos iniciais pretendiam, sobretudo, trazer à luz elementos significativos para a história da formação dos profissionais da Educação Física e, por isso, tinham interesse somente para um público muito circunscrito $(8,9,13)$; mas também nos parece evidente que o estudo sobre as práticas físicas do passado foi, até aos nossos dias, menos considerado do ponto de vista intelectual. Assim, uns, por olharem a educação física como mera manifestação técnico-motora, e outros, por menosprezarem as capacidades culturais dos exercícios corporais, têm contribuído para a incipiente investigação neste domínio.

Com isto, não se pretende dizer que nada se tenha feito durante os últimos anos do século anterior e no início deste. Alguns investigadores (10,14, 20, 27, 29) têm levantado nova informação e possibilitado um melhor conhecimento acerca das concepções e práticas físicas ao longo de várias épocas. Sobretudo, têm procurado interpretar o desenvolvimento dos exercícios corporais como uma manifestação humana num dado contexto sócio-cultural. Levando em atenção esta linha de interpelação da informação e mantendo-nos coerentes com as nossas anteriores investigações $(16,17)$, é nossa intenção trazer, agora, mais alguns elementos capazes de enriquecerem o entendimento da educação física no século XVIII.

Procuraremos, fundamentalmente, equacionar o valor dos exercícios físicos no desenvolvimento dos mais jovens, cruzando informação proveniente de diversas fontes e interpretando-a tendo em conta o contexto científico-cultural da época em que foi produzida. Além disso, tentaremos delimitar os discursos e as práticas, descortinando o sentido dos exercícios corporais e perscrutando as tendências que, então, se evidenciavam.

Como é evidente, os exercícios físicos e os jogos não são privilégio só da nossa época ou civilização.
Ainda, hoje, é possível encontrar inúmeros testemunhos dessas práticas físicas, ao longo do tempo, em várias partes do mundo. Todavia, como tantas outras manifestações características do género humano, se os exercícios corporais são uma constante no percurso do Homem, eles são igualmente marcados pelo tempo, ou seja, são elementos culturais da sociedade, desenvolvendo-se nos limites do pensamento aí produzido. Neste sentido, mais do que definir momentos de ruptura a apontarem o caminhar decisivo da Educação Física em direcção à contemporaneidade, indicaremos o mais evidente sobre o discurso e a prática do exercício físico no século XVIII, mostrando como aí se articulavam as ideias mais inovadoras com as actividades tradicionais.

\section{A IMPORTÂNCIA DO EXERCÍCIO}

Consensual, entre os que se preocuparam com a criação das crianças, era que elas tinham necessidade de fazer exercício, cada vez mais intenso e variado, à medida que se iam desenvolvendo. Aos recém-nascidos, todavia, ainda não se lhes reconhecia essa necessidade, sendo costume comprimirem-se-lhes os membros entre faixas e mantilhas, por isso, só, nos curtos momentos da muda das roupas, as crianças mais pequenas tinham ocasião de moverem os seus membros. Enquanto bebé de colo, a única possibilidade do recém-nascido contactar com a realidade envolvente e de respirar um ar diferente daquele que o envolvia no compartimento em que, normalmente, o deixavam, era através do passeio feito ao colo de alguma pessoa da casa.

Este ciclo de vida, contudo, tinha o seu fim, sucedendo-lhe um outro em que o bebé, por si, começava a querer movimentar-se pelo chão, gatinhando e explorando o espaço pelos seus próprios meios. Nesta idade, na opinião dos médicos, não se devia forçar a natureza, pondo as crianças de pé, e obrigando-as a andar antes de chegada a ocasião própria, o que, normalmente, devia acontecer quase ao fim do primeiro ano, momento do ensaio dos primeiros passos, podendo, no entanto, estas tentativas serem mais prematuras numas do que noutras.

O tentar antecipar-se este momento era, porém, um hábito mantido pelo tempo e um desejo normal da família, uma "gracinha" a contar aos familiares e amigos, o qual tinha implicações nefastas para o futuro. 
Este acelerar da natureza era visto com maus olhos mesmo antes do século XVIII e ilustração disto é o alerta lançado, nos finais da centúria anterior, por Frei Manuel de Azevedo, o qual advertia as amas e as mães para jamais tentarem obrigar os seus filhos a começarem a caminhar (5, p.11). Esta admoestação não surtiu, todavia, o efeito desejado, uma vez que, para antecipar e encurtar o tempo de aprendizagem do andar, se chegaram a usar de alguns artifícios que só, muito recentemente, têm vindo a ser postos de parte, dado considerar-se o gatinhar uma prática de enormes benefícios para a criança.

$\mathrm{Na}$ última década de Setecentos, alguns clínicos saíram mesmo a terreiro para condenar o facto de se ensinar os meninos a andarem mais cedo, utilizando-se, com este intuito, uma espécie de suspensórios ou carrinhos. Em todo o caso, não eram as vantagens do gatinhar que se apontavam, mas antes se salientavam os problemas e as malformações provocados por tais artifícios. As andadeiras, clamava Francisco José de Almeida, "além de opprimirem o peito dos meninos, sustentando-os sobre as pernas", só podiam ser causa de tortura dos que se punham a andar antes que o "osso da canela" tivesse a precisa consistência, o qual, ao torcer-se, levaria consigo os músculos, provocando uma deformidade ou, até, um aleijão (4, p. 76). Apesar dos argumentos dos médicos, estes auxiliares da aprendizagem do andar, quer fossem simples fitas presas às roupas quer carrinhos com rodas mais ou menos sofisticados, deviam ser bastante comuns. Melo Franco, embora os considerasse vantajosos, dado evitarem as quedas frequentes, responsabilizava-os pelas "tortuosidades das pernas, e má conformação das últimas vértebras do espinhaço" e, principalmente, pelos graves danos visíveis nos ossos da bacia de muitas mulheres, causa de tantas dificuldades nos partos (18, p. 88-89).

No entendimento dos esculápios de finais de Setecentos, desde o momento que as crianças chegassem à idade de andar, só era necessário conceder-lhes total liberdade de movimentos e espaço adequado para o tentarem fazer. Contudo, devia-se vigiá-las para que, através de alguma queda mais violenta, não se molestassem excessivamente. Para isso, bastaria uma casa espaçosa e pouco adornada, onde não fosse possível chegar a objectos que as pudessem magoar, e ter o cuidado de não se entregar o menino aos cuida- dos de outras crianças mais velhas que, na sua inconsciência, pudessem vir a facilitar mais perigos do que vigilância. Bastaria, portanto, deixar agir a natureza que, a seu tempo, tudo viria. Asseverava Manuel Henriques de Paiva no final do século: "Não he preciso ensinar as crianças a andar; deixem-se rolar e mover de huma para outra parte sobre tapetes, cobertores etc., porque este exercício as vigora, e com elle se habituam pouco a pouco a usar dos braços, e pernas, de sorte que aos seis meses pouco mais ou menos, poderão andar sós" (24, p. 18). Enquanto bebés, a tendência geral era para se conservarem em casa, bem resguardados e agasalhados, no temor de que algo os molestasse, fosse o frio ou qualquer má intenção de um olhar invejoso e maléfico; quando mais crescidos, era a falta de quem os pudesse levar até locais aprazíveis e saudáveis, onde, além de brincarem e correrem, pudessem respirar o ar puro, uma vez que os pais, ocupados na labuta do dia-a-dia, poucas disponibilidades teriam para proporcionarem aos filhos tais regalias. Mais felizes seriam as crianças no campo, os filhos das gentes de menores riquezas, que sairiam, neste particular, relativamente favorecidas. Fora de portas, brincando livres de vigilância apertada, por certo, melhor expandiriam todas as suas energias e imaginação em jogos, brincadeiras e correrias próprias da meninice. Em vantagem nítida, estavam, é claro, os filhos da aristocracia mais proeminente. As casas que habitavam, já de si espaçosas, dispunham geralmente de quintas, pátios, jardins, varandas e terraços, onde era possível passarem grande parte do dia em brincadeiras sem fim, reunindo, à sua volta, outras crianças da casa, amigos e parentes. Além disso, era também normal deslocarem-se aos arredores da cidade, em passeios, bem como a alguma das residências de que a família dispusesse. Os momentos festivos e de reunião familiar eram especialmente propícios a que as crianças dessem largas às suas actividades preferidas. Enquanto os adultos se entretinham entre si, a liberdade e o tempo de actuação delas aumentava. Às crianças, de seu natural irrequietas, pouco mais seria preciso de acordo com os médicos dos finais de Setecentos, do que proporcionar-lhes o espaço suficiente para se movimentarem, porque logo cumpriam essa parte fundamental do seu desenvolvimento (30, p.41-42). Todavia, lembrando as de sua 
natureza mais indolentes, havia quem salientasse a vantagem de as estimular, dado o exercício ser absolutamente necessário, na primeira idade, para endurecer os músculos ainda fracos e dissipar, com a transpiração, a humidade que se pensava sobejar nos meninos (18, p. 91). Usando a forma interrogativa, argumentava Francisco José de Almeida acerca da inevitabilidade e utilidade da natureza buliçosa das crianças: "E como filtrará o figado a colera, se os musculos abdominaes não o comprimirem para ajudar hum circulo de si froxo, e vagaroso? Como se corroborarão os membros, se elles se não moverem? As digestões serão tardias, e imperfei-tas; o quylo não poderá passar se as pequenas forças do menino não forem ajudadas por hum longo, e vivo exercicio (...). Nesta idade se decide da sorte do homem; trata-se de fazer hum individuo molle, enfermo, triste, e pezado, ou hum animal vigoroso, sadio, alegre, e util?" (4, p. 91).

As considerações, em torno das vantagens do exercício físico, multiplicavam-se. O exercício moderado conservava a vida e o calor natural, consumia as superfluidades, corroborava as faculdades, era o logro do tempo e o inimigo do ócio, bem como o devido à mocidade e gozo da velhice $(28$, p. 108). Mas para que o exercício fosse benéfico, algumas regras teriam de ser observadas, designadamente, quanto ao momento da sua prática mas também da sua duração e intensidade. Sendo demasiado, corria-se o risco de se "adelgaçarem" os humores, fazendo nascer "defluxos, incendios, febres" a poderem levar até à "dissipação" desses mesmos humores e das "partes solidas" (1, 21, p. 494-495 e 23, p. 399). Perante tais efeitos perversos, recomendava-se a sua prática apenas até que o corpo se pusesse "corado, e quente", começando a suar (1, 21, p. 493 e 28, p. 108) e, de preferência, pela manhã, em jejum, quando estava feita a digestão da ceia e o estômago se encontrava vazio, porque, fazendo evacuar os excrementos do dia anterior, melhor se dispunha o corpo para receber o novo alimento $(1,21$, p. 493-494 e 28, p. 108).

Em todo o caso, e para se considerar exercício, não bastava mexer o corpo, uma vez que só os movimentos feitos com algum vigor, e que acelerassem a respiração, podiam ser tidos como tal. Assim, consideravam-se exercícios capazes de ajudarem à conserva- ção da saúde e ao desenvolvimento do homem, práticas como os jogos de bola, da péla e do volante, a natação, a esgrima, a dança, a corrida e o andar a cavalo e a pé $(24$, p. 58$)$. Todavia, nem todos os exercícios eram tidos por adequados às crianças mais novas. A estas reservava-se a corrida e demais jogos próprios da meninice e também os exercícios da voz, como cantar e declamar (19, p. 243-246). Mas desaconselhava-se, por exemplo, o aprender a nadar, nos rios e no mar, que já, então, era considerado um dos mais completos e úteis exercícios, no entanto, remetia-se a sua aprendizagem para a entrada do menino na puberdade. Para as raparigas, desta idade, devia preferir-se a dança, equivalente à equitação e à esgrima para os rapazes, porque, além de dar graça e harmonia aos movimentos, habituava à correcta posição do corpo (19, p. 239-240). Os exercícios eram assim definidos como adequados tanto pela presunção da capacidade dos corpos como pelo preconceito cultural regulado pela hierarquia das idades ou pela desigualdade sexual.

Apesar disso, em perfeita sintonia com as tendências da medicina e da pedagogia europeia, os médicos portugueses, mais ousados, dos finais de Setecentos atribuíam, de facto, tão grande importância ao exercício físico na formação global do indivíduo que aconselhavam os pais a não reprimirem o instinto lúdico das crianças. O seu entendimento era de que não se devia mesmo castigar as crianças que cometessem excessos nas suas brincadeiras uma vez que era despropositado castigá-las por aquilo de que dependia a sua saúde e robustez $(18$, p. 91). Como se depreende, eram entusiásticos defensores de que se deixasse as crianças brincarem a seu bel-prazer, correndo e saltando a qualquer hora do dia. Chegavam, até, a exortar os mestres a ensinarem as crianças através de divertimentos e brincadeiras e a intervalarem a instrução com momentos de recreio, dado a contenção corporal provocar a saturação intelectual (18, p. 92 e 24, p. 27).

\section{JOGOS E RECREIOS}

Como já vimos, os exercícios físicos das crianças deviam apenas circunscrever-se a corridas e a jogos próprios da idade. Ora, entre os jogos apropriados aos mais pequenos, contavam-se o do pião, o da 
bola, o da péla, o do truque, o do toque emboque, o do talo e o da conca. Francisco José de Almeida advogava mesmo que os adultos, sempre que tal se mostrasse necessário, desafiassem a natural actividade e vivacidade das crianças "ensinando-lhes a jogar a pella" e depois "a bolla e o bilhar" (4, p. 79) e Henriques de Paiva ia ainda mais longe, ao defender que "os jogos de bilhar, da laranjinha, da pella, o correr, bailar" e outras actividades se deviam suceder umas às outras e misturarem-se mesmo com as "occupações sérias", sem atender à rigidez dos horários (24, p. 27).

Alguns destes jogos foram-se perdendo na memória dos tempos, mas outros chegaram até nós com maiores ou menores adaptações, por vezes, mudando só o nome por que se conhecem. Por exemplo, o talo jogava-se com dois paus sendo um, o talo, do diâmetro de um dedo polegar e quase um palmo de comprimento, afiado em ambas as pontas, e o outro três ou quatro vezes maior que o primeiro, mas sensivelmente da mesma grossura. À frente de um muro, fazia-se uma cova e o objectivo do jogo consistia em atirar o talo ao muro, distância previamente estabelecida, de modo a fazê-lo cair na cova. Não acertando, o outro jogador devia bater com o pau maior numa das pontas do talo, fazendo-o saltar e, enquanto no ar, darlhe uma pancada que o fizesse cair na cova. Este jogo praticava-se ainda há alguns anos atrás, sendo conhecido, nas Beiras, por bilharda.

Um outro jogo, ainda praticado em algumas localidades portuguesas, era a conca, hoje, normalmente conhecida por malha. Jogava-se com três pedras, uma, espetada no chão, a servir de termo ou baliza e, as outras, para serem atiradas pelos jogadores, desde a distância marcada, devendo acertar na baliza. Mais pontuava quem mais próximo ficava do objectivo, o que se podia medir a olho nu ou, nos casos duvidosos, a palmos ou com auxílio da palhinha ou fio. Muito curiosa era a recomendação feita de vigiar para que, ao tomar a medida, não se fizesse batota, dado se gerarem, destes actos repetidos, hábitos difíceis de tirar depois, como o de furtar e "fazer outras semelhantes indecencias" (2). Aliás, e de forma geral, proibiam-se aqueles jogos mais susceptíveis de criarem maus hábitos, como era o caso dos jogos de sorte e azar (10, p. 378-379 e 15, p.
193-196). Não era, por acaso, que, no Regimento e estatutos do Colégio dos Reis de Vila Viçosa, se autorizava, no tempo destinado à recreação, a jogar alguns dos "jogos honestos" já mencionados, mas se proibiam os de cartas e dados ou qualquer um a dinheiro (26, p. 612).

Quanto aos mais velhos, sendo filhos das famílias mais abastadas, reservavam-se outros exercícios, como a esgrima, a dança e a picaria, especialidades a fazerem parte dos planos de estudos do Colégio dos Nobres e do Colégio de Mafra e que, segundo os estatutos destas instituições educativas, os alunos deviam praticá-los, diariamente, entre as cinco e as sete e meia da tarde, no horário de Verão, ou seja, desde a Páscoa até aos finais de Agosto (11, p. 403 e 12, p. 15). Também do plano de educação particular que a viúva do embaixador em Viena de Áustria, Ambrósio Freire de Andrade e Castro, mãe do futuro marechal Gomes Freire de Andrade, traçava para seu filho, fazia parte o aprender a dançar, a jogar o florete e a montar a cavalo (3). Por sua vez, confessava o Marquês de Fronteira, referindo-se à sua vida de miúdo, que, nas visitas feitas com o seu irmão ao Colégio dos Ingleses, se divertiam a jogar florete e a péla, a andar a cavalo e a dançar (6, p. 122). Aliás, a convivência com ingleses, presentes em Portugal na sequência das Invasões Francesas, proporcionaria aos nobres meninos, longas e excitantes cavalgadas, entre Benfica e Oeiras, levadas a cabo tanto de dia como de noite (6, p. 134-135).

É natural, no entanto, que, quando se tratasse de instituições destinadas aos filhos de gente menos bem posicionada na escala social, fosse diferente, o que se estipulava para os alunos. No Colégio de Alcobaça, dava-se a primazia aos passeios ao ar livre, nas tardes dos dias feriados, tempo em que todos os alunos deviam ir passear pelas "cercas immediatas ao Mosteiro" e pela quinta do Colégio, estabelecendo-se ainda que, um dia por mês, todos os do colégio iriam passar o dia na quinta, em "recreação" (22, p. 88-89). O mesmo se passava com os alunos do Seminário de S. Caetano, em Braga, que passeavam nas tardes dos domingos e dias feriados, excepto, no Advento e Quaresma, períodos em que tinham de ir ouvir sermão numa das igrejas da cidade. Nesses dias, o passeio era substituído por uma volta pela 
cidade "ou seus arrabaldes" (7, p. 38). No Colégio de Nossa Senhora da Graça, no Porto, os passeios só tinham lugar "humas vezes por outras em cada semana" $(25$, p. 6$)$.

Mais vulgar ainda que os passeios, eram as horas de recreação, durante as quais os alunos se ocupariam livremente em "jogos innocentes", com excepção dos de cartas $(25$, p. 6), devendo, todavia, manter um comportamento adequado, sem gritos, nem arremedos e, tão pouco, brigando (7, p. 45). Essas seriam as ocasiões aproveitadas por eles para a prática dos seus jogos e brincadeiras preferidas, de acordo com os seus interesses e as suas idades.

Estes momentos de lazer, presentes em quase todos os horários dos estabelecimentos educativos, particularmente, nos que recebiam porcionistas, obedeciam aos princípios defendidos pelos educadores-moralistas que louvavam as virtudes dos exercícios físicos e dos jogos, desde que estes fossem controlados de modo a não ocuparem demasiado tempo e a servirem os propósitos da educação preconizada, recusando, por isso, tudo o que pudesse conduzir ao abuso, à desonestidade e à violência. Segundo eles, a prática física era útil na medida em que afastava as crianças da ociosidade e as aliviava do enfado dos estudos. A partir de meados do século de Setecentos, porém, estes objectivos complementavam-se com as novas ideias médico-sanitárias a salientarem que o exercício físico, além de natural, era imprescindível à manutenção da boa forma e da saúde das pessoas. Todavia, se os estabelecimentos educativos tinham necessidade de demonstrar que atendiam às propostas higienistas de médicos e pedagogos, raramente eram explícitos quanto ao tipo de práticas a propiciarem. Na maioria dos casos, os seus planos de estudo aludiam apenas a tempos livres para recreação e passeio (17, p. 150). Depreendemos, assim, que não existia qualquer espaço estruturado para aplicação de exercícios físicos sistemáticos e que os jogos ocorriam nestes momentos de lazer e se realizavam espontaneamente seguindo a tradição, ou seja, de acordo com os interesses das crianças e os condicionalismos culturais da época.

\section{CONCLUSÃO}

Quando olhamos o discurso médico produzido no século XVIII, reconhecemos existir nele uma postura crítica face a práticas a implicarem com a formação do corpo. No geral, médicos e cirurgiões reconheciam a necessidade de inverter a tendência da conformação dos corpos pelos ditames da passividade ou da acção mínima. Para eles, independentemente da parte do século a que pertenciam, a prática física foi sempre considerada de grande importância para a preservação da saúde, daí advogarem o exercício físico especialmente para aqueles que eram dados ao gozo da boa mesa e à vida sedentária. No entanto, com o avançar da segunda metade do século, foi-se acentuando a importância do exercício físico para a formação do indivíduo, o que lhe conferia uma maior qualidade pedagógica e o remetia definitivamente também para o espaço da educação. A partir de então, vemos convergir duas tendências desencadeadoras de um movimento favorável ao desenvolvimento do corpo. De um lado, os jogos e as mais práticas físicas legadas pelos séculos anteriores e, do outro, concepções médico-pedagógicas preocupadas, sobretudo, com as condições higiénicas e o desenvolvimento dos indivíduos.

Como vimos, as práticas descritas testemunham tanto a permanência de técnicas corporais ancestrais privilegiadoras de critérios de elegância e posturas artificiais como o contemplar de espaços vocacionados para práticas físicas a servirem as preocupações higiénicas e pedagógicas. Contudo, olhando com mais atenção, os exercícios corporais aparecem fundamentalmente associadas a uma concepção de educação física higiénica ou tradicional. De facto, embora os filhos da aristocracia, quer nos Colégios dos Nobres e de Mafra quer numa educação doméstica, tivessem tempos especialmente dedicados à dança, à equitação e à esgrima, a generalidade dos meninos, a dedicarem-se aos estudos, apenas conhecia espaços de recreação ou horas de passeio. Sendo assim, os exercícios sistemáticos estavam reservados principalmente àqueles que deviam exibir refinamentos corporais sublinhadores da sua situação social; para os outros, disponibilizavam-se tempos a deverem permitir a recuperação de energias necessárias a uma melhor aprendizagem e a oportunidade de momentos lúdicos propiciadores de desenvolvimento físico. 
Contudo, à maioria da população, infantil e juvenil, restava-lhe gerir o desenvolvimento do corpo ao ritmo permitido pelas possibilidades da sobrevivência ou da exigência do trabalho.

\section{CORRESPONDÊNCIA}

\section{José Vítor Ferreira}

Faculdade de Ciências do Desporto

e de Educação Física

Universidade do Porto

Rua Plácido Costa, no 91

4200-450 Porto

Portugal

jferreira@fcdef.up.pt

\section{FONTES E BIBLIOGRAFIA}

Fontes manuscritas

1. B.F.M.P. [170?]. Reservados: Pontos para os exames de Cirurgia, Sessão $5^{\mathrm{a}}$, Capítulo $4^{\circ}$.

2. B. N. L. (1742). Reservados: Methodo breve e claro de jogar a bilharda, pião, e conca: dedicado e offerecido ao sereníssimo senhor D. José Arcebispo e senhor de Braga pelo P.e Francisco Monteiro reytor do Collegio da Comp. a da mesma cidade, Doc. $26, \mathrm{n}^{\circ} 144$.

3. B. P. E. [170?]. Reservados: Plano de educasam para meu filho, Doc. C I X/ 1-10, nº 24.

\section{FONTES IMPRESSAS E BIBLIOGRAFIA}

4. Almeida, F. J. (1791). Tratado da educaçaõ physica dos meninos, para uso da naçaó portugueza. Lisboa: Na Officina da Academia Real das Sciencias.

5. Azevedo, D. M. (1668). Correcção de abusos introduzidos contra o verdadeiro methodo da medicina: em três tratados: o primeiro do grande proveito que a todos faz o exercício; \& de quanto proveitosas são as purgas no principio das enfermidades. $O$ segundo de como convem as sangrias dos pés, primeiro que as dos braços, nas enfermidades que cometem cabeça, \& coração. O terceiro do conhecimento, \& curaçao da febre maligna, com os remédios mais particulares, $\mathcal{E}$ experimentados para melhor se curar; $\mathcal{E}$ do modo mais conveniente, $\mathcal{E}$ proveitoso para se fazerem as juntas de médicos: e para se curarem com mais brevidade todas as chagas, $\mathcal{E}$ feridas de qualquer qualidade que sejão. Lisboa: Na Officina de Diogo Soares Bulhoens.

6. Barreto, D. J. T. M. (1926). Memórias do Marquês de Fronteira e d'Alorna. Coimbra: Imprensa da Universidade.

7. Brandão, D. F. C. (1861). Plano de educação dos meninos órfãos e expostos do Seminário de S. Caetano feito na anno de 1801. Braga: Typ. dos Órfãos.

8. Cabral, J. C. T. (1973). Síntese da evolução das principais correntes da Educação Física em Portugal no período compreendido entre 1900 e 1940. Separata do Boletim do INEF. Lisboa: Publicação do Centro de Investigação, Documentação e Informação.

9. Crespo. J. (1972). História da Educação Física em Portugal. Os antecedentes da criação do INEF. Ludens. 2: 47-52.

10. Crespo, J. (1990). A história do corpo. Lisboa: Ed. Difel.

11. Estatutos do Collegio Real de Nobres da Corte, e cidade de Lisboa (1761). In Andrade, A. A. B. (1981). A reforma pombalina dos estudos secundários (1759-1771): (Contribuição para a história da pedagogia em Portugal). Coimbra: Coimbra Editora.

12. Estatutos do Real Collegio de Mafra (1772). Lisboa: Na Regia Officina Typographica.

13. Estrela, A. (1972). Elementos e reflexões sobre a Educação Física em Portugal no período compreendido entre 1834 e 1910. Separata do Boletim do INEF. Lisboa: Publicação do Centro de Investigação, Documentação e Informação.

14. Ferreira, A. G. (2000). Gerar, criar, educar: a criança no Portugal de Setecentos. Coimbra: Quarteto Editora.

15. Ferreira, V. N. ; Ferreira, A. G. (1990). Os jogos e a moral no Antigo Regime. In Actas do Forum Desporto, Ética, Sociedade. Porto: UP. FCDEF.

16. Ferreira, J. V. N. (1999). Olhares sobre o corpo no séc. XVIII: saúde, práticas físicas e bem-estar. Tese de Doutoramento. Porto: UP. FCDEF. Texto policopiado. 
17. Ferreira, J. V. ; Ferreira, A. G. (1999). Olhar sobre a educação física, em Portugal, nos finais do Antigo Regime. Revista Portuguesa de Pedagogia. 2: 147-152.

18. Franco, F. M. (1790). Tratado da educaçaó physica dos meninos para uso da naçaõ portugueza. Lisboa: Na Officina da Academia Real das Sciencias.

19. Franco, F. M. (1814). Elementos de hygiene ou dictames theoreticos, e practicos para conservar a saúde, e prolongar a vida. Lisboa: Na Typografia da Academia, vol. 2.

20. Hasse, M. (1993). O divertimento do corpo. Corpo, lazer e desporto, na transição do século XIX para o século XX, em Portugal. Tese de Doutoramento. Lisboa: UTL. FMH. Texto policopiado.

21. Henriquez, F. F. (1721). Anchora medicinal para conservar a vida com saude. Lisboa Occidental: Na Officina da Musica.

22. Mendonça, Fr. M. (1776). Regulamento das escolas do Collegio de Alcobaça ordenado conforme o que determinam os estatutos da Universidade de Coimbra e dispõem as instruç̧ões gerais'o qual por ordem do illustrissimo, e reverendíssimo D. Abade Geral visitador, e reformador da Real Congregação de Santa Maria de Alcobaça da Ordem de S. Bernardo, Fr. Manoel de Mendonça do Conselho de Sua Magestade fidellissima, seu esmoler mór e donatario da comarca de Alcobaça, se formou para uso do nosso collegio. Lisboa: Na Regia Officina Typografica.

23. Monravá, D. (1747). Novissima medicina impugnante á nova, velha, e velhissima dos autores antigos, e modernos, em quatro tomos dividida. Lisboa: Na Officina do mesmo autor, vol.1.

24. Paiva, M. J. H. (1787). Aviso ao povo ou summario dos preceitos mais importantes, concernentes á creação das crianças, ás differentes profissões e officios, aos alimentos e bebida, ao ar, ao exercicio, ao somno, aos vestidos, á intemperança, á limpeza, ao contagio, ás paixões, ás evacuações regulares, E् , que se devem observar para prevenir as enfermidades, conservar a saude, e prolongar a vida. Lisboa: Na Officina Morazziana.

25. Plano que deve observar-se ácerca da educação, e ensino dos porcionistas, que houverem de ser admittidos, para este fim, no Real Collegio de N. Senhora da Graça, e Meninos Órfãos desta cidade do Porto (1813).

26. Regimento, e Estatutos do Collegio dos Reys de VillaViçosa (1645). In Sousa, D. A. C. (1745). Provas da historia genealogica da casa real portugueza. Lisboa: Na Regia Officina Sylviana e da Academia Real, vol. IV.

27. Rosário, Trovão (1996). O desporto em Portugal: Reflexo e projecto de uma cultura. Lisboa: Instituto Piaget.

28. Sá, J. F. F. (1723). Epithome cirurgico, medicinal, observante questeonado, dividido em tres livros com muytas observações medicas, \& cirurgicas, \& hum antidotario de varios remedios tirados de vários autores, $\mathcal{E}$ outros inventos seus. Lisboa Oriental: $\mathrm{Na}$ Officina Ferreyriana, Parte I.

29. Serra, M. Cameira (1998). Os jogos tradicionais. As relações entre as práticas lúdicas e as ocupações agrícolas e pastoris. Tese de Doutoramento. Vila Real: UTAD. Texto policopiado.

30. Villeneuve, J. R. (1767). A aia vigilante ou reflexões sobre a educação dos meninos, desde a infância até à adolescência. Lisboa: Na Officina Ferreyriana. 